\title{
Green Synthesized Gold Nanoparticle from Kigelia Africana Enhanced the Antibacterial and Antioxidant Activities: An In Vitro Approach
}

\author{
${\text { Gunasekaran Vetrichelvi }{ }^{1}, \text { Kannan Elangovan }^{2}, \text { S. Niranjali Devaraj }}^{3}$ \\ ${ }^{1}$ Department of Biochemistry, University of Madras, Guindy Campus, Chennai-600025, Tamilnadu, India \\ ${ }^{2} \mathrm{CAS}$ in Botany, University of Madras, Guindy Campus, Chennai-600025, Tamilnadu, India \\ ${ }^{3}$ Professor, Department of Biochemistry, Guindy Campus, University of Madras, Chennai-600025, India
}

\begin{abstract}
Medicinal plants are widely used by the Indian population since it has no harmful side effects and low cost compared to other treatments. In the $21^{\text {st }}$ century, nanotechnology field is expected to be the base for all the important technological innovations. From that, green synthesis of gold nanoparticle is gaining more momentum due to its commercial demand besides it plays a significant role in the medical and biomedical applications. Spherical gold nanoparticles isolated from the leaf extract of Kigeliaafricana were studied by $U V$-visible spectroscopy. The green synthesized KaGNPs considerably exhibited strong radical scavenging potential (77. 54\%) when compared to the aqueous leaf extract (66. 09\%). Further KaGNPs inhibited the growth of human pathogens both Gram-positive and Gram-negative.
\end{abstract}

Keywords: Gold nanoparticle, Antibacterial, Antioxidant

\section{Introduction}

Nanotechnology is one of the most active area of research in modern materials science, because of its modern applications and have emerged rapidly as one of the most promising multidisciplinary branch of sciences which embraces numerous diverse fields of science and technology ranging from agricultural, advanced materials, biomedical, chemical science, electronics, environmental, information technology, pharmaceutical, and textile as well as to generate new applications in biotechnology and nanomedicine.

The smaller size and high surface of nanoparticles are the key factors which make them reliable to biomedical fields. , due to its drug carrier properties[1]. Nanomaterials are capable to exhibit high drug loading and releasing capacity, ability to target malignant cells and low toxicity, thus it is appropriate for therapeutic applications [2]. Gold nanoparticles (AuNPs) have many potential applications in biological and biomedical fields due totheir high biocompatibility, stability and the distinct surface plasmon properties[3]. Colloidal KaGNPs have been recommended for diverse biomedical applications because of its unique surface, electronic and optical properties [4]. Synthesis of nanoparticles using plants are advantageous than other biological processes because it can be scaled up suitably for large-scale production (Shankar et al. , 2004). At present, green nanotechnology is quite new, the full scope of technological improvement in the field of human health care products [5].

Plant-derived compounds identified as promising agents and it was successfully translated to marketable drugs. Whereas the cancer prevention field has developed, many researchers have turned and tuned towards plants to identify and isolate new potential bioactive compounds to analyse the chemopreventive and chemotherapeutic efficacy [6].
Kigeliaafricana (Lam), belongs to the family Bignoniaceae. It is widespread across India, Africa, Ghana, Sierra Leone, Gambia, Sudan, and Nigeria [7]. [8], have reported Sexual complaints such as infertility, poor libido, sexual asthenia and impotence are treated with medicines containing the fruits, roots or leaves of $K$. africana.

Human beings are often infected by microorganisms such as bacteria, molds, yeasts and viruses present in their living environments. [9]. Multidrug resistance is the most important problem caused by the chemical antimicrobial agents. Their efficacy depends on the specific binding with surface of the microbial cell. Therefore, an alternative way to overcome the drug resistance is needed, especially in medical devices[10].

The detailed approach was considered to explore the potential of bioactive compound towards reduction and capping of gold nanoparticles. In this work, synthesis and its characterization was achieved their antibacterial activity and antioxidant ability was tested. Investigations of phytochemicals has been making rapid progress and becoming popular as sources of promising anticancer compounds[11]. In recent years, the prevention of many disorders such as cancer and cardiovascular diseases has been found to be concomitant with the ingestion of fresh fruits, vegetables, tea or plant beverages that are rich in natural antioxidants[12].

\section{Materials and Methods}

\section{1. Materials}

Chloroauric acid, DPPH (1, 1 Di-phenyl picrylhydrazyl) were obtained from Sigma-Aldrich Chemicals. Mueller Hinton Agar (MHA) was obtained from Hi-Media. 


\section{International Journal of Science and Research (IJSR) \\ ISSN (Online): 2319-7064}

Index Copernicus Value (2013): 6. 14 | Impact Factor (2015): 6. 391

Fresh leaves of Kigeliaafricana were collected from University of Madras, Guindy campus, Chennai, Tamil Nadu, India. All glasswares were sterilized by autoclave.

\section{2Preparation of plant extract and synthesis of gold nanoparticles}

Fresh leaves of $K$. africana were washed several times with tap water to remove dust and dirt and it was cut into small pieces and $8 \mathrm{~g}$ of leaves were boiled with $100 \mathrm{~mL}$ of double distilled water for $15 \mathrm{~min}$ and it was filtered using WhatmanNo. 1 filter paper. Synthesis of gold nanoparticles were done by reducing $1 \mathrm{mM}$ of chloroauric acid $(195 \mu \mathrm{L})$ with $50 \mathrm{~mL}$ of leaf extract at room temperature.

\section{3 Purification of gold nanoparticles}

The completely phyto-reduced sample on treatment with acetone (1:4 proportion) undergoes aggregation which can then be separated by centrifugation and redispersion. The obtained pellet was washed and re-dispersed in sterile distilled water to produce nanoparticles free from biochemical constituents[13].

\section{4 Characterization of Nanoparticles}

\section{4. 1 UV-vis spectral analysis}

The reduction of pure gold ions was monitored by measuring the UV-vis spectrum of the reaction medium at 30 min after diluting a small aliquot of the sample with distilled water and a spectrum was read at a wide range of 200 to $800 \mathrm{~nm}$ (UV Vis spec - Shimadzu).

2. 4. 2 Determination of hydrogen donation ability (DPPH assay)

The ability of theKaGNPsto scavenge the stable free radical was assessed by the method of Leong \&Shui[14]. Briefly, a 0 . $1 \mathrm{mM}$ solution of DPPH in methanol was prepared. An aliquot (20-100 $\mu \mathrm{L})$ of KaGNPs was added to $3 \mathrm{~mL}$ of methanolic DPPH solution. Methanol alone served as blank and DPPH in methanol without KaGNPs served as positive control. After 30 minutes of incubation, the discolouration of the purple colour was measured at $517 \mathrm{~nm}$ and radical scavenging activity was calculated as follows:

$$
\text { FRSA }=\left[\left(A_{\mathrm{c}}-A_{\mathrm{s}}\right) / A_{\mathrm{c}}\right] \times 100
$$

Where $A_{\mathrm{c}}$ is the absorbance of the control and $A_{\mathrm{s}}$ is the absorbance of the tested sample after $60 \mathrm{~min}$.

\section{4. 3 Assessment of antibacterial activity}

The antibacterial activity of green synthesized KaGNPs were tested against six bacterial isolates using Agar well diffusion method [15]. Mueller Hinton Agar plates were inoculated with $100 \mu \mathrm{L}$ of standardized culture $\left(1.5 \times 10^{8} \mathrm{CFU} / \mathrm{ml}\right)$ of each bacterium (in triplicates) and spread with sterile swabs. $6 \mathrm{~mm}$ wells were made using sterile cork borer and different aliquots were added $(25,50,75$ and $100 \mu \mathrm{L})$ into the wells. The plates were left 10 minutes at room temperature to allow diffusion of samples. After incubation for $24 \mathrm{~h}$ at $37^{\circ} \mathrm{C}$, the plates were observed. Zone of inhibition was measured and expressed in millimetres as well as the average diameter of inhibition zone was taken for evaluating the antibacterial activity of the extracts.

\section{Results and Discussion}

\section{1 UV-visible spectral analysis}

The leaf extract of $K$. africana was mixed with $\mathrm{HAuCl}_{4}(0.1$ $\mathrm{mM}$ ) solution, the reduction of gold ions was confirmed after 30 min with the gradual appearance of yellow to pink colour and the surface plasmon resonance (SPR) of the KaGNPs formed at $536 \mathrm{~nm}$ (Fig. 1). UV-vis spectroscopy is an efficient technique to determine the formation and stability of AuNPs. The Plasmon bands were broad with and tail in the longer wavelength region that extends well into the infrared region in colloidal solution. Similar was the findings of [16] and [17], who had reported that the natural extract act as a reducing agent for synthesis of nanoparticles. The intensity of surface plasmon peak was directly proportional to the density of the nanoparticles in solution [18].

Table 1: Preliminary screening of phytochemicals from leaf extract of Kigeliaafricana

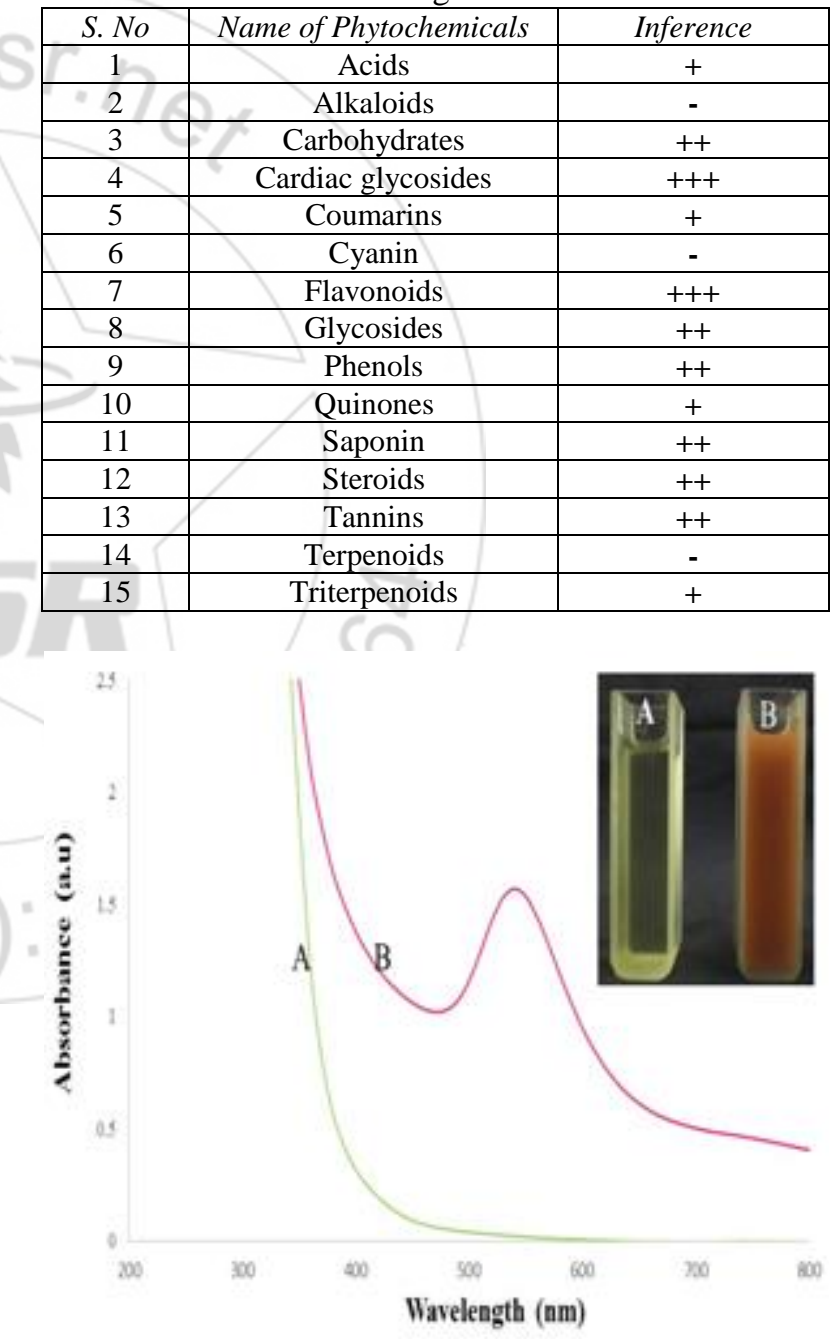

\section{2. Antibacterial activity}

The therapeutic potential of KaGNPs has been explored by in vitro antibacterial assay. Phyto-fabricated gold nanoparticles exhibited dose-dependent antibacterial activity against all the test organisms. The maximum zone of inhibition obtained were against E. coli $(23 \mathrm{~mm})$ and followed by $P$. aeruginosa $(21) S$, typhi $(19 \mathrm{~mm})$ and $S$. 


\section{International Journal of Science and Research (IJSR) \\ ISSN (Online): 2319-7064}

Index Copernicus Value (2013): 6. 14 | Impact Factor (2015): 6. 391

aureus $(18 \mathrm{~mm})$ respectively. Concentration of gold nanoparticle were limited $(500 \mu \mathrm{g})$, because higher dosage will lead to the toxic towards host pathogens. Whereas the least activity was obtained in $25 \mu \mathrm{g} / \mathrm{mL}$ against $S$. aureus $(6$. $5 \mathrm{~mm}$ ) and also absence of zone of inhibition were recorded against both in $S$. typhiand $P$. aeruginosa at $25 \mu \mathrm{g} / \mathrm{mL}$ concentration. From these results it was concluded that an increase in the concentration of KaGNPs might be helpful for the scientific communities to overcome from certain bacterial diseases. Earlier findings (Zhao and Nalwa, 2007) stated that gold nanoparticles will bindinto the nucleus itself which allows them to diffuse through the nuclear pores. The variations in zone of inhibition might be due to the bacterial cell wall composition [23]. The synthesized AuNPs from Menthapiperita was active against Gram negative (E. coli) and Gram positive (S. aureus) microorganisms (Ali et al., 2011).

Table 2: Antibacterial activity of KaGNPs against four human pathogens

\begin{tabular}{|c|c|c|c|c|c|c|}
\hline S. no & Human pathogens & $\begin{array}{c}\text { Concentration } \\
(\mu \mathrm{g} / \mathrm{mL})\end{array}$ & \multicolumn{4}{|c|}{$\begin{array}{c}\text { Zone of inhibition } \\
(\mathrm{mm})\end{array}$} \\
\hline 1 & $\begin{array}{c}\text { Staphylococcus } \\
\text { aureus }\end{array}$ & 25 & 6.5 & & 9.0 & - \\
\hline 2 & Salmonella typhi & 50 & 9 & 10.5 & 15.0 & 11 \\
\hline 3 & Escherichia coli & 75 & 14.5 & 15 & 19.0 & 16 \\
\hline 4 & $\begin{array}{c}\text { Pseudomonas } \\
\text { aeruginosa }\end{array}$ & 100 & 18 & 19 & 23.0 & 21 \\
\hline $\begin{array}{l}+++ \\
+\end{array}$ & $\begin{array}{l}\text { - Strongly Positive } \\
\text { - Trace }\end{array}$ & - & & & & \\
\hline
\end{tabular}

\section{3 Antioxidant activity}

The in vitro free radical scavenging activity of both aqueous extract and KaGNPs was performed using (Leong \&shui, 2005). The green synthesized KaGNPs exhibited better results (77. $54 \pm 4.19)$ when compared to that of aqueous extract (66. $09 \pm 4$. 14), but the standard (BHT) showed improved results when compared to both aqueous extract and gold nanoparticles. The antioxidant properties of $K$. africana and its role against diseases associated with oxidative stress as well as the composition of phenolics and flavonoids compounds would have contributed to the antioxidant activities of the plant[24]. The DPPH radical scavenging of $\mathrm{HAuCl} 4$ showed low percent of inhibition when compared to the gold nanoparticles which might be due to less catalytic activity of salts and less solubility of metal oxides [25]. The earlier report incdicated that the methanolic extract of $S$. monoica stem possessed 116. $22 \%$ of radical- scavenging activity at $800 \mu \mathrm{g} / \mathrm{mL}$. When compare to the findings of [25], the present study revealed (66. $09 \%)$ and $(77.54 \%)$ of radical scavenging activity both in aqueous and KaGNPs at $100 \mu \mathrm{g} / \mathrm{mL}$.

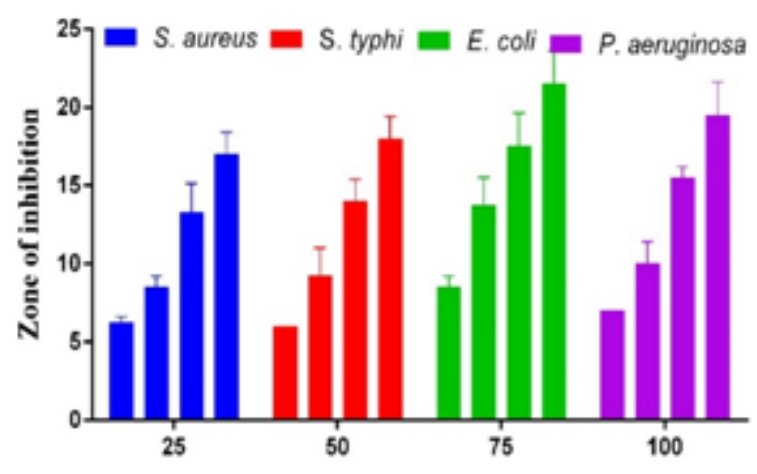

\section{Conclusion}

The nano-revolution explains significant role of plants for green synthesis of nanoparticles. The present study focussed towards green chemistry approach with eco-friendly nature for synthesis of gold nanoparticles using aqueous leaf extract of $K$. africana. The phytochemicals such as cardiac glycosides, carbohydrates, flavonoids and phenols acted as reducing and capping agents for the preparation of KaGNPs. UV-Vis spectra is the important factor to confirm concentration of reducing agent and reaction time of the nanoparticles. The synthesized KaGNPs were stable for one month without aggregation and mostly spherical with an average size of $18.75 \mathrm{~nm}$ and it could offer a massive scope for use in medical field as an efficient antimicrobial agent. Besides, it is cost- effective, eco-friendly, non-toxic and easily renewable.

\section{Acknowledgement}

The authors gratefully acknowledge the Director, CAS in Botany, University of Madras, Guindy Campus, Chennai600025 , for providing the laboratory facilities and National Centre for Nanosciences and Nanotechnology (NCNSNT), University of Madras, for providing instrumentation facilities.

\section{References}

[1] K. Chatterjee, S. Sarkar, K. J. Rao, S. Paria, Core / shell nanoparticles in biomedical applications, Adv. Colloid Interface Sci. (2014). doi:10. 1016/j. cis. 2013. 12. 008.

[2] K. Vimala, S. Sundarraj, M. Paulpandi, S. Vengatesan, S. Kannan, Green synthesized doxorubicin loaded zinc oxide nanoparticles regulates the $\mathrm{Bax}$ and $\mathrm{Bcl}-2$ expression in breast and colon carcinoma, Process Biochem. 49 (2014) 160-172. doi:10. 1016/j. procbio. 2013. 10. 007.

[3] Y. W. S. Gunasekaran, Spectroscopic and microscopic investigation of gold nanoparticle nucleation and growth mechanisms using gelatin as a stabilizer, (2012). doi:10. 1007/s11051-012-1200-2.

[4] J. -G. Leu, S. -A. Chen, H. -M. Chen, W. -M. Wu, C. -F. Hung, Y. -D. Yao, et al. , The effects of gold nanoparticles in wound healing with antioxidant epigallocatechin gallate and $\alpha$-lipoic acid. , Nanomedicine. 8 (2012) 767-75. doi:10. 1016/j. nano. 2011. 08. 013.

[5] P. Mohanpuria, N. K. Rana, S. K. Yadav, Biosynthesis of nanoparticles: technological concepts and future 


\section{International Journal of Science and Research (IJSR) \\ ISSN (Online): 2319-7064 \\ Index Copernicus Value (2013): 6. 14 | Impact Factor (2015): 6. 391}

applications, J. Nanoparticle Res. 10 (2007) 507-517. doi:10. 1007/s11051-007-9275-x.

[6] F. Aqil, R. Munagala, J. Jeyabalan, M. V Vadhanam, Bioavailability of phytochemicals and its enhancement by drug delivery systems, Cancer Lett. 334 (2013) 133141. doi:10. 1016/j. canlet. 2013. 02. 032.

[7] C. Agyare, D. D. Obiri, Y. D. Boakye, N. Osafo, Medicinal Plant Research in Africa, Elsevier, 2013. doi:10. 1016/B978-0-12-405927-6. 00019-9.

[8] A. A. D. Adeparusi, Eunice Oluwayemisi, Effects of Medicinal Plant (Kigelia Africana) on Sperm Quality of African Catfish Clarias Gariepinus (Burchell, 1822) Broodstock, J. Agric. Sci. (2010) 192-199.

[9] H. Lee, D. Ryu, S. Choi, D. Lee, Antibacterial Activity of Silver-nanoparticles Against Staphylococcus aureus and Escherichia coli, 39 (2011) 77-85.

[10] J. S. Kim, E. Kuk, N. Yu, J. Kim, S. J. Park, J. Lee, et al. , Antimicrobial effects of silver nanoparticles, 3 (2007) 95-101. doi:10. 1016/j. nano. 2006. 12. 001.

[11]E. A. Afolabi C, E. O. Ibukun, Akinmoladun, and E. O. Farombi, Phytochemical constituent and antioxidant activity of extract from the leaves of Ocimum gratissimum, Sci. Res. Essay. 2 (2007) 163 - 166.

[12] P. Anand, A. B. Kunnumakkara, A. B. Kunnumakara, C. Sundaram, K. B. Harikumar, S. T. Tharakan, et al. , Cancer is a preventable disease that requires major lifestyle changes. , Pharm. Res. 25 (2008) 2097-116. doi:10. 1007/s11095-008-9661-9.

[13]F. A. A. Rajathi, R. Arumugam, S. Saravanan, Phytofabrication of gold nanoparticles assisted by leaves of Suaeda monoica and its free radical scavenging property, J. Photochem. Photobiol. B Biol. (2014). doi:10. 1016/j. jphotobiol. 2014. 03. 016.

[14]L. . Leong, G. Shui, An investigation of antioxidant capacity of fruits in Singapore markets, Food Chem. 76 (2002) 69-75. doi:10. 1016/S0308-8146(01)00251-5.

[15]I. Ahmad, A. Z. Beg, Antimicrobial and phytochemical studies on 45 Indian medicinal plants against multi-drug resistant human pathogens, J. Ethnopharmacol. 74 (2001) 113-123. doi:10. 1016/S0378-8741(00)00335-4.

[16]C. Jayaseelan, R. Ramkumar, A. Abdul, P. Perumal, Green synthesis of gold nanoparticles using seed aqueous extract of Abelmoschus esculentus and its antifungal activity, Ind. Crop. Prod. 45 (2013) 423-429. doi:10. 1016/j. indcrop. 2012. 12. 019.

[17] A. Annamalai, V. L. P. Christina, D. Sudha, M. Kalpana, P. T. V Lakshmi, Colloids and Surfaces B : Biointerfaces Green synthesis, characterization and antimicrobial activity of Au NPs using Euphorbia hirta L. leaf extract, Colloids Surfaces B Biointerfaces. 108 (2013) 60-65. doi:10. 1016/j. colsurfb. 2013. 02. 012.

[18] A. Ahmad, P. Mukherjee, S. Senapati, D. Mandal, M. I. Khan, R. Kumar, et al. , Extracellular biosynthesis of silver nanoparticles using the fungus Fusarium oxysporum, Colloids Surfaces B Biointerfaces. 28 (2003) 313-318. doi:10. 1016/S0927-7765(02)00174-1.

[19] N. Basavegowda, A. Idhayadhulla, Y. R. Lee, Phytosynthesis of gold nanoparticles using fruit extract of Hovenia dulcis and their biological activities, Ind. Crops Prod. 52 (2014) 745-751. doi:10. 1016/j. indcrop. 2013. 12. 006.

[20] P. J. Babu, P. Sharma, S. Saranya, U. Bora, Synthesis of gold nanoparticles using ethonolic leaf extract of Bacopa monnieri and UV irradiation, Mater. Lett. 93 (2013) 431-434. doi:10. 1016/j. matlet. 2012. 11. 034.

[21] S. Kunjiappan, R. Chowdhury, C. Bhattacharjee, A green chemistry approach for the synthesis and characterization of bioactive gold nanoparticles using Azolla microphylla methanol extract, Front. Mater. Sci. 8 (2014) 123-135. doi:10. 1007/s11706-014-0246-8.

[22] J. Lim, S. P. Yeap, H. X. Che, S. C. Low, Characterization of magnetic nanoparticle by dynamic light scattering. , Nanoscale Res. Lett. 8 (2013) 381. doi:10. 1186/1556-276X-8-381.

[23] K. B. Ayaz Ahmed, S. Subramanian, A. Sivasubramanian, G. Veerappan, A. Veerappan, Preparation of gold nanoparticles using Salicornia chiata plant extract and evaluation of catalytic and antibacterial activity. , Spectrochim. Acta. A. Mol. Biomol. Spectrosc. 130C (2014) 54-58. doi:10. 1016/j. saa. 2014. 03. 070.

[24] J. P. Kamdem, A. Adeniran, A. A. Boligon, C. V. Klimaczewski, O. O. Elekofehinti, W. Hassan, et al. , Antioxidant activity, genotoxicity and cytotoxicity evaluation of lemon balm (Melissa officinalis L. ) ethanolic extract: Its potential role in neuroprotection, Ind. Crops Prod. 51 (2013) 26-34. doi:10. 1016/j. indcrop. 2013. 08. 056.

[25] C. H. Ramamurthy, M. Padma, I. D. mariya samadanam, R. Mareeswaran, A. Suyavaran, M. S. Kumar, et al. , The extra cellular synthesis of gold and silver nanoparticles and their free radical scavenging and antibacterial properties. , Colloids Surf. B. Biointerfaces. 102 (2013) 808-15. doi:10. 1016/j. colsurfb. 2012. 09. $025 \mathrm{~s}$ 